\title{
Electric communication during courtship and spawning in two sibling species of dwarf stonebasher from southern Africa, Pollimyrus castelnaui and P. marianne (Mormyridae, Teleostei): evidence for a non species-specific communication code?
}

\author{
Bernd Baier ${ }^{1)}$ \& Bernd Kramer \\ (Zoological Institute of the University of Regensburg, Universitätsstraße 31, 93040 \\ Regensburg, Germany)
}

(Accepted: 14 December 2006)

\section{Summary}

The fixed part of the electrocommunication signal, the electric organ discharge (EOD) waveform, is well differentiated in the two vicariant dwarf stonebasher species, Pollimyrus castelnaui and $P$. marianne. However, differentiation regarding the variable, situation-dependent part, i.e., inter-discharge interval (IDI) patterns, has never been studied in a pair of sibling species of mormyrid fish. We here compare the electrical signalling that accompanies different motor behaviours (such as resting and swimming, territorial agonistic interactions, courtship and spawning) in the two species. Double pulse patterns of regularly alternating short IDIs of 8-11 ms and long ones of 16-100 ms accompanied threat displays in both species. In three pairs of $P$. marianne and five pairs of $P$. castelnaui, courtship was characterised by nest building, territory patrolling and acoustic displays (advertisment calls) that were accompanied by long discharge breaks in the male and highly regular IDIs around 50 $\mathrm{ms}$ in the female of both species. Nest-tending males showed IDI sequences consisting of regularly alternating double pulse patterns, similar to threat displays. During spawning both sexes generated stereotyped IDI sequences of a low discharge rate. All IDI patterns occurring in one species were also found in the other, and no species-specifity was identified at that level. Playback experiments contrasting conspecific and heterospecific IDI sequences (that had been recorded from nocturnally swimming fish) revealed preferences in none of the six experimental subjects. Double pulse patterns, high discharge rate displays (HD) and regularisations of the IDI sequence accompanying specific behaviours occurred in similar form in

1) Corresponding author's e-mail address: Bernd.Baier@biologie.uni-regensburg.de

(C) Koninklijke Brill NV, Leiden, 2007 
both dwarf stonebasher species of the present study. Therefore, we conclude that in the speciation of $P$. castelnaui and $P$. marianne the fixed part of the EOD, its waveform, was under more differential selection pressure than its variable part, the patterns of IDI.

Keywords: weakly electric fish, reproduction, differentiation, inter-discharge interval pattern, speciation, electric organ discharge.

\section{Introduction}

Like all members of the African teleost fish family Mormyridae, dwarf stonebashers, Pollimyrus castelnaui and Pollimyrus marianne, generate short electric organ discharges (EODs) of about $1 \mathrm{~ms}$ for object location and communication (review: Kramer, 1990, 1996; Moller, 1995; Hopkins, 1999). The EODs of mormyrids are often species-specific (Bennett, 1971; Hopkins, 1980, 1981) and evoked interest in the question of species and mate recognition (Hopkins \& Bass, 1981; Crawford, 1992; Kramer, 1997; Crawford \& Huang, 1999). In the two morphologically similar dwarf stonebasher species the clearly distinct EOD waveforms (Kramer et al., 2003) appear to have similar functions, as suggested by spontaneous preferences of conspecific over heterospecific EOD waveforms in a two-alternative forced-choice playback experiment (unpublished data).

The waveform of the EOD is the fixed part of the communication signal, whereas the variable, situation-dependent part is represented by interdischarge intervals (IDIs), ranging from about $8 \mathrm{~ms}$ up to several hundred milliseconds. The discharge rate may fluctuate rapidly as excitation changes. The communicative role of specific IDI patterns was experimentally demonstrated by playback (Kramer, 1979; Crawford, 1991). IDI sequences do not only signal and accompany changes in overt behaviour but may also inform about species identity. This was demonstrated in Petrocephalus bovei when it discriminated against playback IDI sequences recorded from Brienomyrus brachyistius and Pollimyrus isidori (Kramer \& Lücker, 1990), and for Campylomormyrus rhynchophorus discriminating against IDI sequences recorded from $C$. tamandua. In the reverse experiment with the latter species pair, juvenile $C$. tamandua did not show a preference for conspecific IDIs over those of $C$. rhynchophorus, in spite of well differentiated IDI sequences (Kramer \& Kuhn, 1994). Compared to these species pairs in the literature, the present one seems to be much more closely related, as suggested by the only recently resolved confusion of their identity (Kramer et al., 2003). Therefore, the dwarf stonebasher species pair offer a unique research opportunity 
for studying the question of differentiation in IDI patterns, the variable part of the EOD.

With these questions in mind we compare the electrical signalling behaviour of both dwarf stonebasher species with a special focus on reproduction. We also conducted playback experiments to test for preferences regarding conspecific over heterospecific IDI patterns.

\section{Methods}

\section{Animals and their care}

Seven P. marianne Kramer et al. 2003 from the Upper Zambezi (seven caught by F.H. van der Bank and B. Kramer in 1999 at Katima Mulilo, Namibia $\left(17^{\circ} 32^{\prime} 31.9^{\prime \prime} \mathrm{S}, 24^{\circ} 26^{\prime} 17.7^{\prime \prime} \mathrm{E}\right)$ and two bred in the laboratory in 2002$)$, and 34 P. castelnaui (Boulenger, 1911) from the Okavango delta (two caught by R. Bills in 2000, at Sepopa, Nguma Lagoon, $18^{\circ} 57^{\prime} 30.6^{\prime \prime} \mathrm{S}, 22^{\circ} 23^{\prime} 12.0^{\prime \prime} \mathrm{E}$, the other specimens caught by F.H. van der Bank in 2002 at Makwena, $19^{\circ} 03^{\prime}$ $45.3^{\prime \prime} \mathrm{S}, 22^{\circ} 23^{\prime} 24.3^{\prime \prime} \mathrm{E}$ ) were available for this study. In the beginning, fish were kept in groups of four to ten animals in tanks of different size (150700 litres). Later on, groups of two and three per tank were formed. Three male/female pairs of $P$. marianne were kept in tanks of 150, 200 and 400 litres, and a group of two females and one male in a tank of 800 litres. Six male/female pairs of $P$. castelnaui were kept in 150-1 tanks for three years. The remaining fish were kept in groups of two and three in a 800-1 tank for shorter periods. Sex was determined by a kink in the base of the anal fin of adult males, a reliable feature in many mormyrid species (Iles, 1960; Skelton, 2001), and also in dwarf stonebashers (Kramer et al., 2003). Standard length of the fish was $4.5-7 \mathrm{~cm}$ in P. marianne and $4.0-6.5 \mathrm{~cm}$ in $P$. castelnaui. The maximum length given for $P$. castelnaui is $7 \mathrm{~cm}$ (Skelton, 2001; Kramer et al., 2003). All animals were exposed to a light/dark cycle of $12 / 12 \mathrm{~h}$ and were fed freshly defrosted, sometimes also live chironomid larvae. Temperature was kept at $23-27^{\circ} \mathrm{C}$, while water conductivity ranged from $40-250 \mu \mathrm{S} / \mathrm{cm}$, usually $90-110 \mu \mathrm{S} / \mathrm{cm}$. The tanks were densely planted with Java moss (Vesicularia dubyana) and Cryptocoryne sp. and provided rocks and porous pots for shelter. 


\section{Recording and analysis of the overt and electrical behaviour}

The methods of recording and individually assigning IDI sequences followed Scheffel \& Kramer (2000, 2006) and Werneyer \& Kramer (2002, 2005).

The discharges of the fish were recorded with carbon rod electrodes (length, $25 \mathrm{~cm}$, diameter, $0.5 \mathrm{~cm}$ ). Three to six electrode pairs were permanently installed in the tanks in order to detect all EODs regardless of the fishes' position. EODs were amplified by multichannel differential amplifiers (GVI 2 or 3, electronics workshop of the University of Regensburg, Germany), and separately stored on magnetic tape, either of an eight-channel, true-to-waveform instrumentation tape recorder (model Racal Store Plus VL, Racal Inc., Southampton, UK), or a four-channel videorecorder (model Panasonic AG 7350, Matsushita Electric Industrial, Osaka, Japan). Stored EODs were A/D- converted at a sampling rate of $100 \mathrm{kHz}$ on four channels in sections of 33 s (Hydra Light process computer with H109 ADC module, Kinzinger Systeme, Rastadt, Germany), and saved on the hard disk of a personal computer for further analysis using the program package Diadem 8.1/9 (National Instruments, Austin, TX, USA). During the course of this study the recording system was expanded by a second H109 module allowing for a six-channel online digitization at a sampling rate of $50 \mathrm{kHz}$ per channel.

The overt behaviour of the fish was videotaped using an infrared-sensitive camera (model FK 6990 B-IQ, Cohu, San Diego, CA, USA; lens, Pentax/Cosmicar 1.0: 8-48 mm, Tokyo, Japan), and infrared illumination with no visible light (model UF 500 FL, Derwent Systems, Cramlington, UK). A synchronous time reference signal that was stored in parallel channels facilitated offline analysis of overt and electrical behaviours.

To assign EODs to specific individuals, two criteria were used: the slight inter-individual differences in EOD waveform, and the history of amplitude and polarity changes that were correlated with the movements of the fish. This was done by eye, scrolling through the records, because automatic assignment of EODs was not reliable enough (due to the similarity of EOD waveforms in individuals of the same species).

At least once a month, each tank was observed for at least one hour at different times of the night, and the behaviour of the fish recorded. Whenever indications for reproductive behaviour (like nest-building or increased territorial behaviour) were recognised, the observations and recordings at this tank were extended to the whole night. These observations were centred 
on the male but interactions with the other fish were also recorded ('focal sampling', Martin \& Bateson, 1993). The present study is based on a total of about $200 \mathrm{~h}$ of video- and electrical recordings. Usually, only short IDI sequences from 30-60 s were analysed, except for one spawning pair of $P$. castelnaui (one hour without interruptions). Five hours of IDI sequences from interacting fish and $10 \mathrm{~h}$ from isolated fish were analysed.

\section{Playback experiments}

In order to simultaneously play back two IDI sequences to an experimental subject, the test tank $(100 \times 50 \times 50 \mathrm{~cm})$ was fitted with two dipoles in the function of signal sources (two vertically orientated carbon rods with diameter $5 \mathrm{~mm}$; separation, $2.5 \mathrm{~cm}$ ) and two pairs of carbon rod electrodes for recording. The dipoles were placed at a distance of $30 \mathrm{~cm}$ to the left and to the right of the experimental subject's hiding pot that was placed in the centre of the apperatus, and each connected to one custom-built D/A-converter with memory (DAM, electronics workshop of the University of Regensburg, Kramer \& Weymann, 1987), that were both controlled by a personal computer. For playback we used biphasic, single-cycle sinusoids of $0.25 \mathrm{~ms}$ duration and an FFT peak amplitude frequency of $3.5 \mathrm{kHz}$ that bore no resemblance to natural EODs of the species studied.

For each experimental animal we used four stimulus IDI sequences, two from two $P$. castelnaui and two from two $P$. marianne individuals of both sexes. We selected sections of 1024 IDIs for playback that had previously been recorded from freely swimming, individually held fish. We chose nocturnal 'swimming' IDI sequences from isolated fish rather than 'resting' or 'interaction' patterns because 'swimming' patterns have succesfully been used in earlier studies (Kramer \& Lücker, 1990; Kramer \& Kuhn, 1994), allowing for better comparison of results. From each species one IDI pattern with a relatively small and one with a wide IDI range was chosen (Table 1).

The field strength of the playback signals corresponded to that generated by adult $P$. castelnaui or $P$. marianne. We measured the electric field strength of five fish (three $P$. castelnaui and two $P$. marianne) with a dipole made from a pair of vertically orientated glassy carbon rods (Sigradur G, HTW GmbH, 86672 Thierhaupten, Germany; diameter, $1 \mathrm{~mm}$; length, $6 \mathrm{~cm}$, insulated except for the lowest $3 \mathrm{~mm}$; rod separation centre-to-centre, $1 \mathrm{~cm}$ ) positioned at the centre of the apparatus (replacing the hiding pot, while a fish replaced 
Table 1. Descriptive statistics of 'swimming' IDI sequences used for playback.

\begin{tabular}{|c|c|c|c|c|}
\hline \multirow[t]{2}{*}{ Species IDI pattern \# } & \multicolumn{2}{|c|}{ P. castelnaui } & \multicolumn{2}{|c|}{ P. marianne } \\
\hline & Pattern \#1 & Pattern \#2 & Pattern \#1 & Pattern \#2 \\
\hline Sex & $\sigma^{\top}$ & 우 & $\sigma^{7}$ & q \\
\hline IDI Min (ms) & 15 & 12 & 16 & 9 \\
\hline IDI Mean \pm SD $(\mathrm{ms})$ & $48.5 \pm 24.7$ & $37.9 \pm 8.3$ & $45.1 \pm 16.9$ & $35.0 \pm 10.1$ \\
\hline IDI Max (ms) & 141 & 82 & 185 & 88 \\
\hline Mean difference between & & & & \\
\hline successive IDIs $\pm \mathrm{SD}(\mathrm{ms})$ & $13.2 \pm 13.9$ & $3.4 \pm 4.5$ & $11.1 \pm 12.4$ & $5.2 \pm 4.7$ \\
\hline Mean EOD rate $(\mathrm{Hz})$ & 20.6 & 26.4 & 22.1 & 28.6 \\
\hline Mode of histogram (ms) & 55.7 & 38.0 & 46.0 & 38.0 \\
\hline
\end{tabular}

one of the playback dipoles). The measuring dipole was rotated to record the maximum peak-to-peak amplitude. The averaged field strength generated by the fish $(N=5)$, as measured in this way, was $342 \pm \mathrm{SD} 8 \mu \mathrm{V} / \mathrm{cm}$. This was the field strength the experimental subjects received at the position of the hiding pots during stimulation experiments (accuracy $\pm 2 \%$ ).

A test series consisted of 16 single tests per experimental subject. In each single test one stimulus source presented a conspecific IDI sequence, while the other one presented a heterospecific IDI sequence. We used a randomized blocks design (Cochran \& Cox, 1957) that sampled each combination of IDI sequence with right/left side presentation equally often in a random sequence. Tests started only two days after introducing a fish into the test tank, and were conducted exclusively at night. In each single test the signals were presented for $180 \mathrm{~s}$. Signal presentation started when the fish was hiding in the centre of the apparatus.

We tested each fish individually for the null hypothesis of no difference between the times the fish vistited the lateral compartments holding the signal sources. These compartments were marked by lines on the aquarium bottom and were clearly visible on the monitor. The lines divided the tank into three equally sized compartments. The visiting times were estimated by an observer in real time, using two stopwatches.

The statistic test used was the paired $t$-test for comparison between species, and the significance level was set to $\alpha=0.05$. To also check for significant differences in visiting times within a species' IDI patterns we used a one-way-ANOVA followed by a Tukey post test. 


\section{Results}

Non-reproductive behaviour

Patterns of IDI sequences in isolated fish

Six $P$. marianne and $10 P$. castelnaui all changed their behaviour from a nearly motionless hiding ('resting') state during light hours to a restless, active ('swimming') state at night. All fish were individually kept in isolation.

The IDI sequences reflected this day-night shift. Figure 1 shows typical examples of IDI sequences recorded during 'resting' and 'swimming', together with IDI histograms for both species. Table 2 summarises histogram modes and EOD rates measured in 16 individuals for 'resting' and 'swimming' IDI sequences.

During the day, IDIs ranged from 8 to $300 \mathrm{~ms}$, always with a prominent mode at about 14-16 ms and a second distinct mode at about $75 \mathrm{~ms}$. In some individuals a third mode at about $200 \mathrm{~ms}$ was recognisable. IDI sequence plots showed short accelerations of three to seven very short intervals (about 10-15 ms) interspersed throughout long sections of low discharge activity (long IDIs). These accelerations occurred at a rate of one to two per second.

During nocturnal swimming the IDI range was reduced, and only one histogram mode was present in both species (at about 30-50 ms). Both very short IDIs $(<15 \mathrm{~ms})$ and long IDIs $(>100 \mathrm{~ms})$ were rare during the night. Different swimming activities could not be correlated with particular IDI patterns.

EOD rates and histogram modes did not differ significantly between the two species, neither during nocturnal swimming nor day-time resting ( $t$-test, $p>0.18$, see Table 2).

Patterns of IDI sequences during interactions

Owing to the great similarity of EOD waveforms within a species, we were unable to individually assign EODs recorded from groups larger than three animals, but typical overt group behaviours shall be described. In groups of four to ten animals of the same species, a single large male excluded all other fish aggressively from certain areas of the tank in both species. The remaining fish which included females and small males, ranged freely throughout the rest of the tank with no overt aggression among them. 


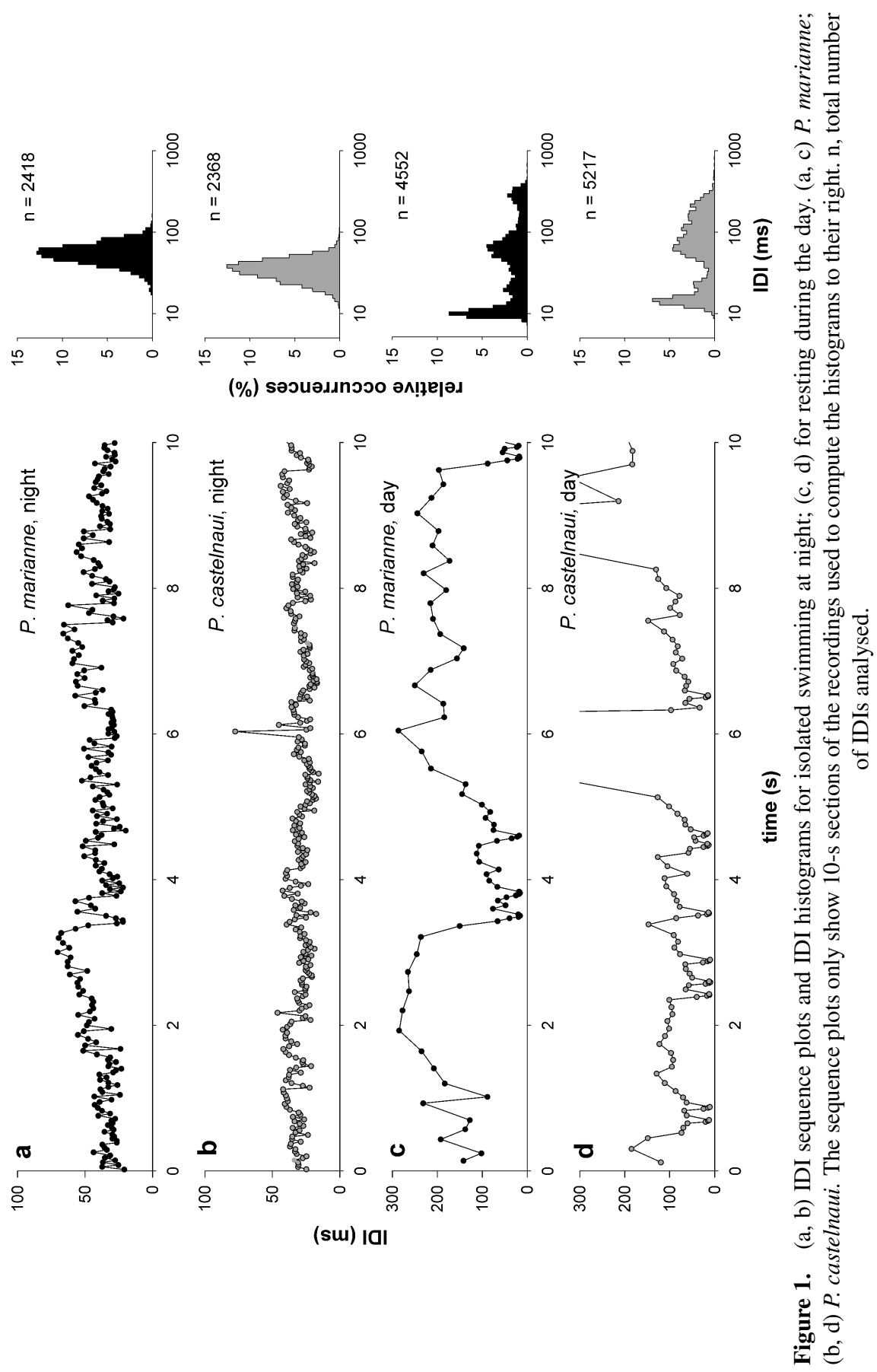


Table 2. Statistics of 'resting' and 'swimming' IDI sequences from $P$. castelnaui $(N=10)$ and $P$. marianne $(N=6)$ in isolated fish.

\begin{tabular}{|c|c|c|c|c|c|c|c|}
\hline & & \multicolumn{2}{|c|}{ P. castelnaui } & \multicolumn{2}{|c|}{ P. marianne } & \multicolumn{2}{|c|}{$t$-test } \\
\hline & & Mean $^{b}$ & SE & Mean $^{b}$ & $\mathrm{SE}$ & $t$ & $p$ \\
\hline \multirow[t]{4}{*}{ Resting } & EOD rate $(\mathrm{Hz})$ & 11.8 & \pm 1.9 & 11.4 & \pm 3.2 & 0.31 & 0.76 \\
\hline & Mode 1 (ms) & 16.1 & \pm 1.9 & 14.2 & \pm 2.4 & 1.42 & 0.18 \\
\hline & Mode 2 (ms) & 68.8 & \pm 7.2 & 82.6 & \pm 20.6 & 1.41 & 0.18 \\
\hline & Mode $3(\mathrm{~ms})^{\mathrm{a}}$ & 178.6 & \pm 34.2 & 284.6 & \pm 40.0 & - & - \\
\hline \multirow[t]{2}{*}{ Swimming } & EOD rate $(\mathrm{Hz})$ & 24.9 & \pm 3.2 & 23.7 & \pm 3.0 & 0.77 & 0.44 \\
\hline & Mode (ms) & 38.5 & \pm 5.8 & 39.4 & \pm 8.6 & 0.79 & 0.45 \\
\hline
\end{tabular}

${ }^{a}$ A third mode was present only in three P. marianne and five P. castelnaui, therefore, no significance test was performed.

${ }^{\mathrm{b}}$ One mean per individual (based on 3-5 recordings representing at least $15 \mathrm{~min}$ ) was used to estimate these means.

In both species, we observed similar low-aggression behaviours in pairs and groups of three, with individual assignment of EODs over extended periods of time, and we were unable to discern species differentiation in what follows below. Male fish established territories, while females used the remaining parts of the tank. The size of the males' territories depended on the total size of the tank, but was at least $0.2 \mathrm{~m}^{2}$. When another fish approached a male's territory boundary, the resident male usually did not attack immediately, but displayed 'threatening behaviour'. A threatening male approached the intruder, and, when close, would abruptly swim forward for about half its length, only to retreat immediately by swimming backwards for the same distance. While repeating this jerky behaviour for several times the male generated IDI patterns that alternated between 8-12 $\mathrm{ms}$ and 16$100 \mathrm{~ms}$ (Figure 2). When threatened in this way, an intruder usually turned around and left the area without further interaction, whereupon the territory owner resumed its normal motor and electrical activity. In a few instances the intruding fish reciprocated the threat displays (both overt and electrical) of the residential male, at a distance of at least $10 \mathrm{~cm}$. In most cases the intruding fish eventually left the area without fighting, but a few escalating fights were also observed. Fights never exceeded a duration of $20 \mathrm{~s}$ and were characterised by jerky, rapid movements, head butts, bites and HD displays (high discharge rate displays; more than 20 IDIs $<15 \mathrm{~ms}$ ), interrupted by discharge breaks (IDI $>300 \mathrm{~ms}$ ). 


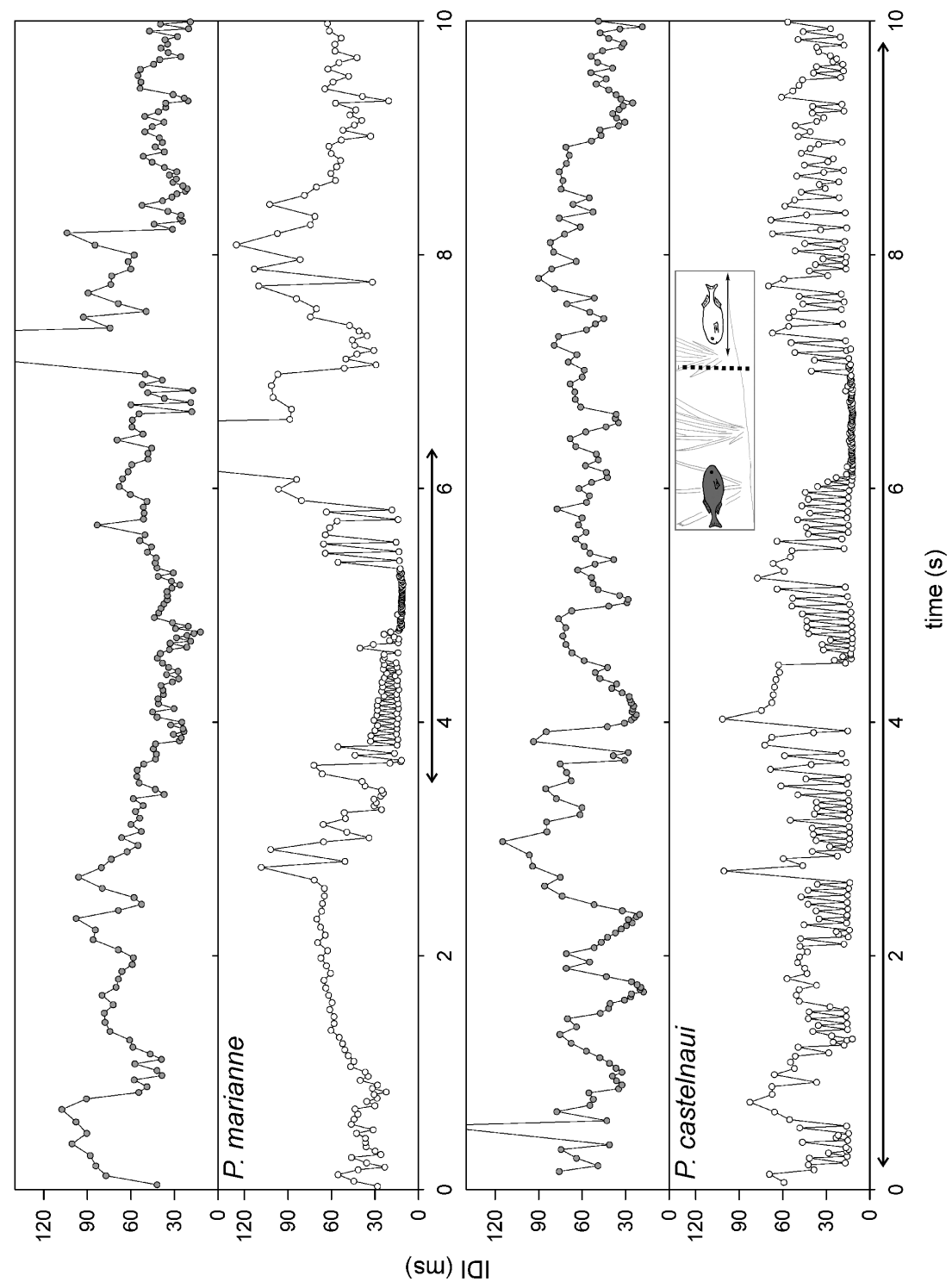


All-out fights more frequently occurred all of a sudden when a fish quickly advanced without discharging (discharge arrest: IDI $>1 \mathrm{~s}$ ) in order to hit. Only then the aggressor started to generate HDs, while the attacked fish started to fight back, also generating HDs (Figure 3). Fights ended as suddenly as they had started when one of the opponents retreated. In all observed cases intruders were driven away by the resident fish. Pronounced chasing was only observed during precourtship (see below).

Females of both species were never observed to defend a territory and similar to groups of four to 10 - females in homosexual pairs, or in groups of two females and one male, were not involved in agonistic behaviour. Interactions between females were typically accompanied by a highly regular discharge activity of only slightly varying IDIs. For example, mean IDIs in a pair of female $P$. castelnaui swimming in close contact to each other were $35 \mathrm{~ms}$ (Figure 4) as was also typical for isolated swimming fish. However, in the former case the mean difference between two adjacent IDIs was much smaller than in the latter (mean difference 2.6 \pm SD $0.9 \mathrm{~ms}$ for two females swimming in close contact for $15 \mathrm{~min}$, vs $9.8 \pm \mathrm{SD} 1.8 \mathrm{~ms}$ for the same two females when in social isolation for $15 \mathrm{~min}$ ).

\section{Reproductive behaviour in P. marianne and P. castelnaui}

We observed courtship and reproductive behaviour in two $P$. marianne pairs, and in two groups of three and five $P$. castelnaui males with together seven females. The overt agonistic and some reproductive behaviours of $P$. marianne were already described by Lamml \& Kramer (2005, 2006), therefore a short summary only of the overt reproductive behaviour for both species is given here, in order to prepare the ground for a more detailed report including IDIs.

The males of both species built nests of about $5 \mathrm{~cm}$ diameter from filamentous plant material, and increased their territorial behaviour by patrolling the whole night and even during the day - a behaviour never seen outside the reproductive period. When patrolling, the fish stopped at the nest site only briefly (Figure 5). During the night male fish vocalised intense courtship

Figure 2. Territorial conflict. Upper panel, P. marianne; Lower panel, P. castelnaui. The male territory owners (white) respond to an approaching intruder fish by jerky to and fro movements while generating a double pulse pattern. The dashed line in the inset indicates the territory border. 


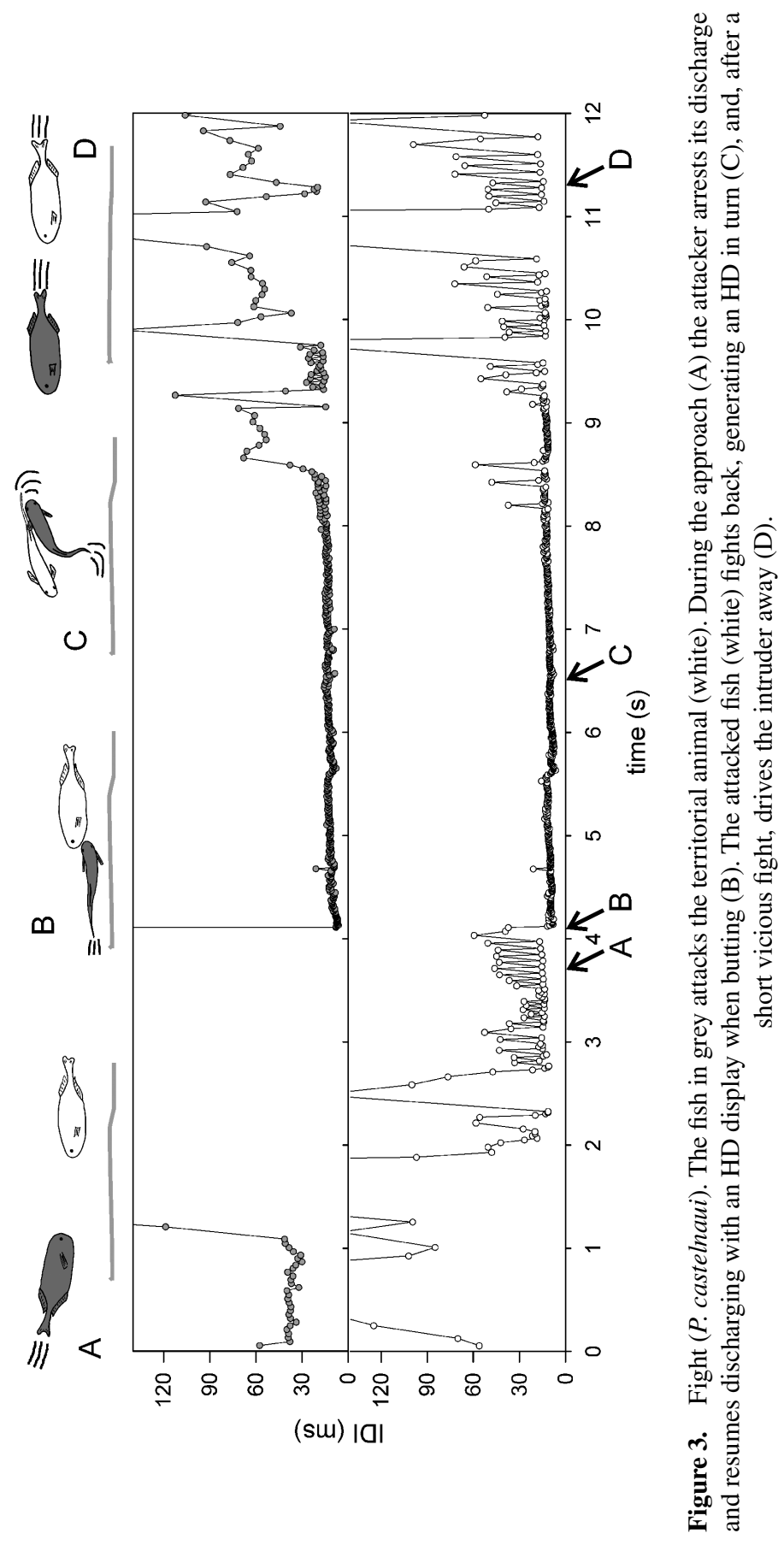




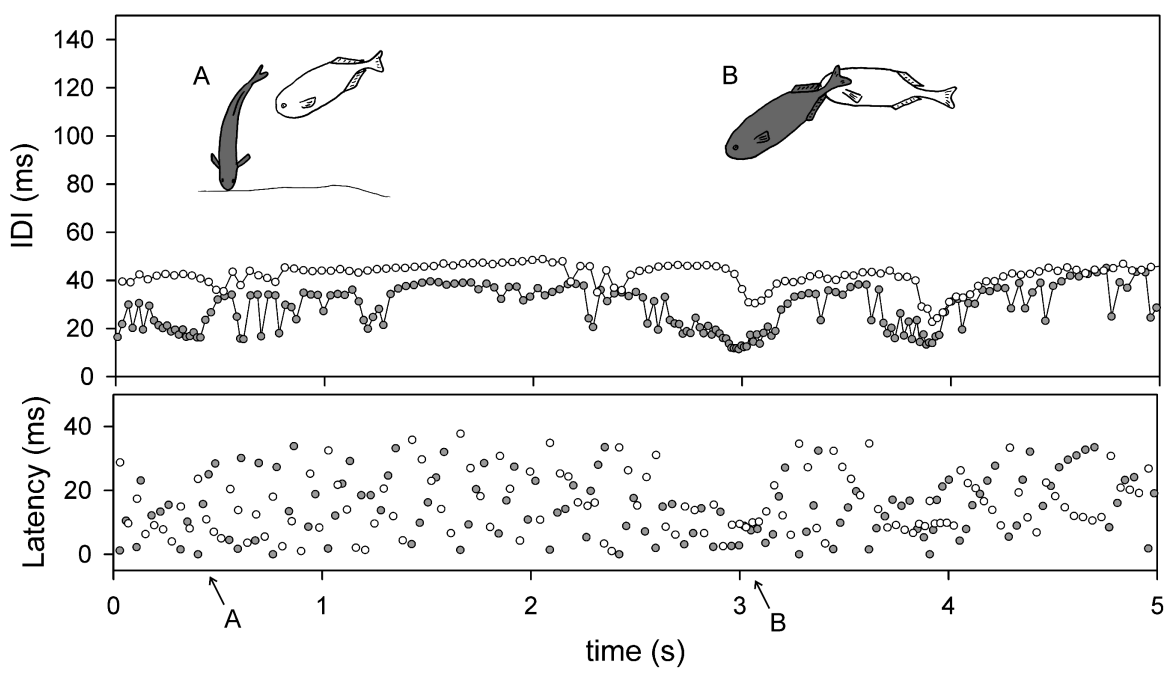

Figure 4. Peaceful interaction between two female $P$. castelnaui swimming in close contact during nocturnal feeding. Note highly regular IDIs especially in 'white' fish (open dots). The lower panel shows the latencies of one fish's pulses to those of the other. Long series of preferred latencies are not present.

songs (Lamml \& Kramer, 2005, 2006). Discharge cessations of up to one minute accompanied the males' patrolling and singing (Figure 6), whereas their discharge activity at the nest site (Figure 7) resembled the regular double pulse pattern also shown when threatening (Figure 2).

In a few cases males stopped all conspicuous activities after some days, but in other cases females repeatedly visited a male's territory. The first visits were short and aggressively terminated by the male that viciously chased the female away. Only after several visiting attempts the male tolerated the presence of the female next to the nest site. When tolerated, a female always displayed a highly regular IDI sequence ranging from 40 to $50 \mathrm{~ms}$.

After precourtship, stereotyped overt interactions between male and female occurred at the prospective spawning site that was $10-80 \mathrm{~cm}$ removed from the nest, but always the same location in one pair. While approaching the male that was always first at the spawning site, the female displayed its typical regular IDI sequence. The male always ceased discharging at least four seconds before the female arrived. When the female reached the spawning site it gradually decreased its discharge rate from 8-10 Hz to about $5 \mathrm{~Hz}$. This is when the male tried to position itself alongside and in parallel to the female, often resulting in circling around a common high axis. The duration 

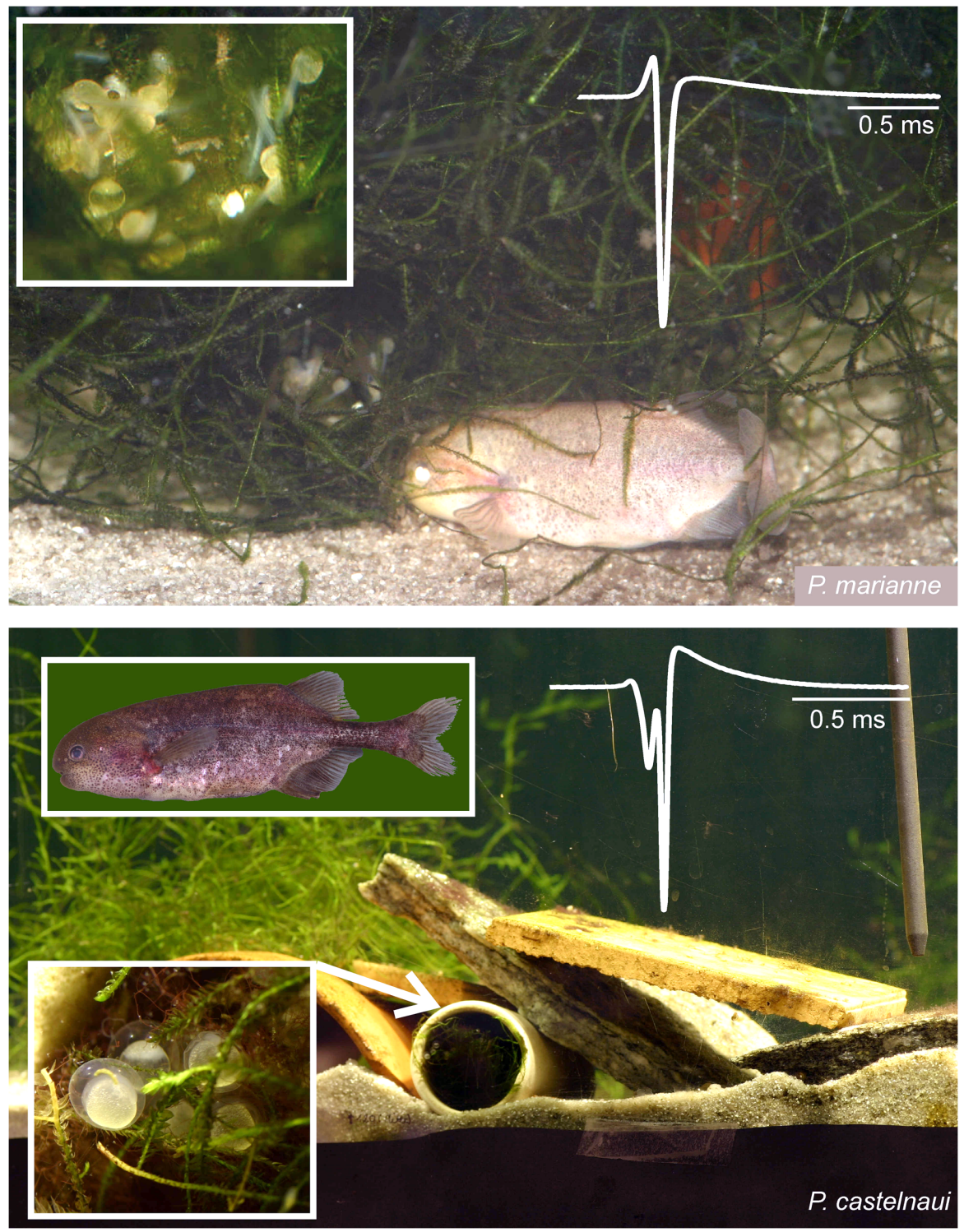

Figure 5. Nest sites of P. marianne, with triphasic EOD waveform, and P. castelnaui, with pentaphasic EOD. In the upper photograph the male checks its nest during the day. The arrow in the lower picture marks the nest position, the male (shown on the upper inset) is hiding in the pot behind the nest. The magnified insets show eggs and alevins. 


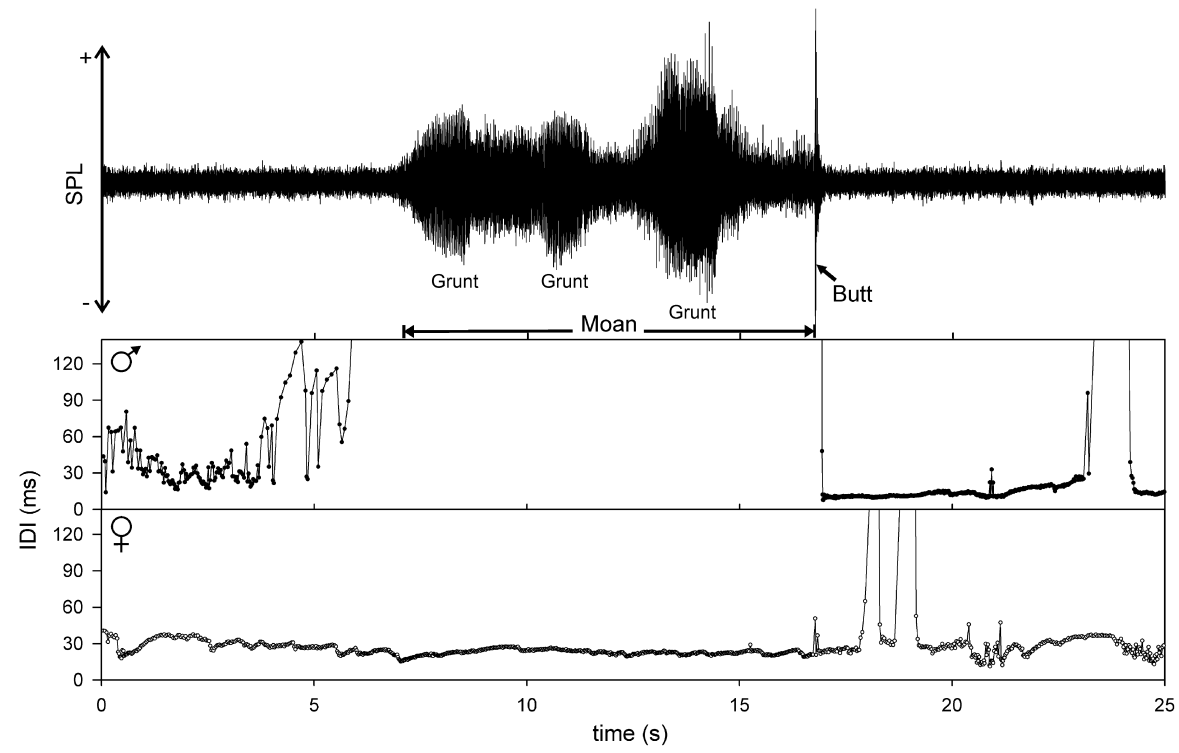

Figure 6. Concurrent electric and acoustic activity during precourtship in P. castelnaui. Upper panel, courtship song of the male (sound pressure level, SPL, over time). Lower panels, IDI sequence plots of male (middle panel) and female. At $5.5 \mathrm{~s}$ the female visits the nest site until the male suddenly attacks her at $16.2 \mathrm{~s}$. During the whole visit the male vocalises a long moan with three superimposed short grunts while arresting its EOD. The high intensity pulse at the end of the moan marks the male's butting the female when he chased her from his territory.

of circling depended on the initial relative positions of male and female and was often skipped altogether, particularly later in a spawning night. Only when the fish reached a parallel position the male started discharging again at a low rate, similar to that of the female. Now the male tried to contact the female's anal fin with its own, sliding its body under the female's. Mostly at the beginning of a spawning night these attempts failed quite often, and were terminated by the female that quickly left the spawning site. The female continued its regular IDI pattern of around $50 \mathrm{~ms}$. In the majority of these instances the male did not show any obvious response, only sometimes it briefly chased the female while generating an HD display.

Only after several failed visits the female allowed the male to slide into a position lateral to its ventral side with anal fins in close contact. After the fish had held this position for about three seconds the female rapidly left the spawning site. The male held its oblique posture for several more seconds, showing slight quivering motions with its whole body, and only 


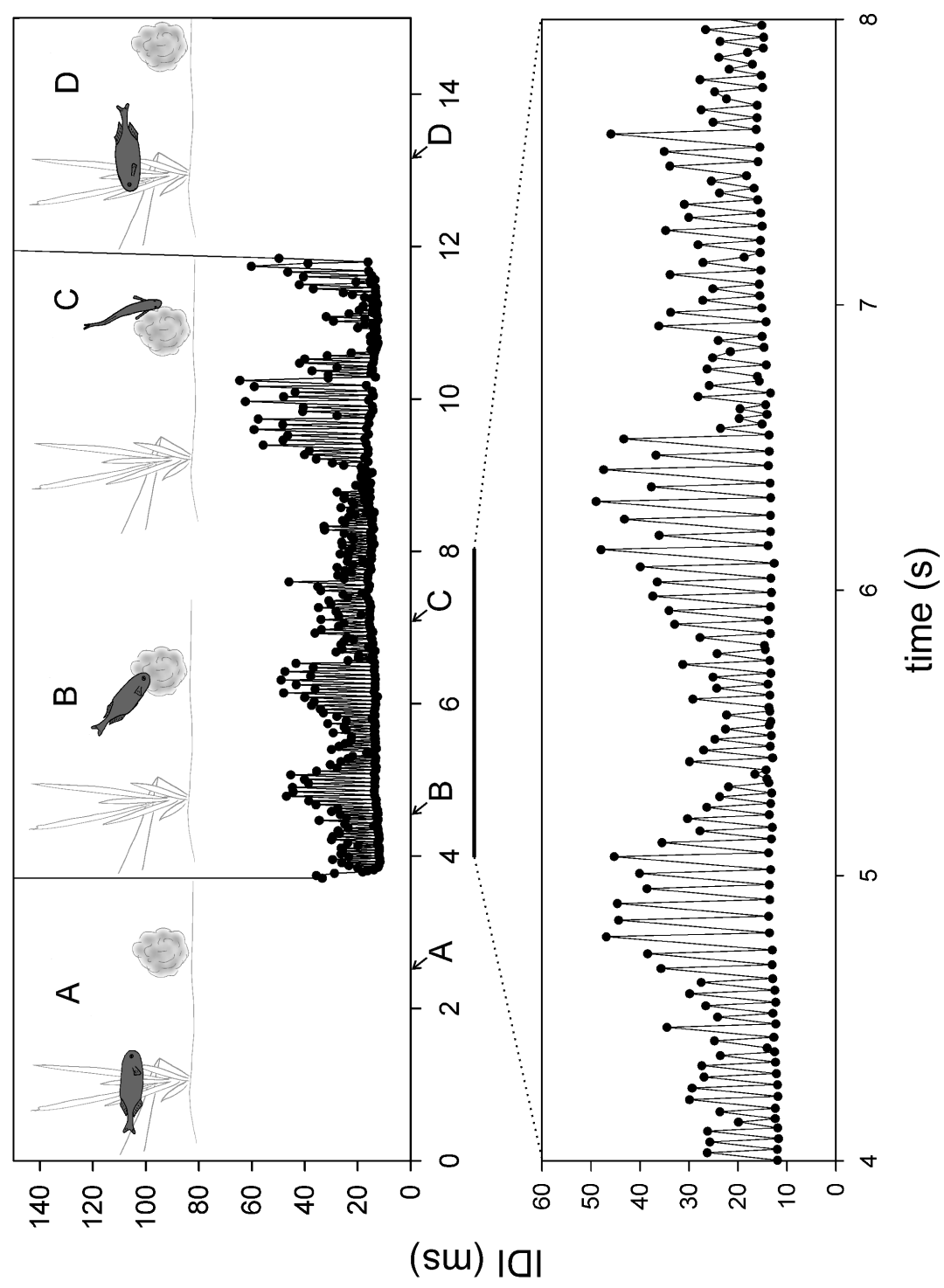


then resumed its normal, upright swimming posture while continuing its discharge arrest. Figure 8 shows the IDI activity and the accompanying overt behaviour drawn from single video frames. Unfortunately, the eggs were too small to be seen on the infra-red video images in 'real time', but were, of course, found next morning (Figure 5). When the male 'woke up' again from what we presume was spawning, it showed searching behaviour at the spawning site. This searching behaviour, a head-down scanning of the spawning area accompanied by a low-rate discharge activity, was followed by a nest visit, during which the male attended to the nest with its mouth, displaying the regular double pulse pattern. Then the male returned to the spawning site and resumed searching. Up to five searching-nest tending turns occurred during which we presume eggs were collected and transported to the nest. Only after the male had finished its search it allowed the next visit of the female that was viciously evicted when arriving too early.

The visits of the female started one to two hours after dark and occurred at a rate of from one per minute to one per several hours, while no visits were observed during the last third of a night. During one spawning night a female visited a male's territory for several dozen times.

The IDI activity differed characteristically between the two sexes in a courting and spawning night (Figure 9). The male mostly generated short IDIs during agonistic encounters and regular sequences of double pulse patterns during nest visits, while the female mostly produced regularisations (i.e., IDI sequences of nearly constant length) during interactions with the male, or typical 'swimming' IDI sequences when outside the male's territory.

\section{Comparison of P. castelnaui's and P. marianne's behaviour}

As far as we could ascertain, overt as well as electrical motor patterns that occurred in one species also occurred in the other. In isolated resting and swimming individuals there were no significant differences in EOD rates or position and number of histogram modes between the two species (Table 2). This was also true for threatening behaviour that was observed in three pairs

Figure 7. Nocturnal nest checking by a male P. castelnaui. Only when immediately at the nest the male generated EODs in a double pulse pattern. When patrolling its territory this male arrested its EOD activity. The lower panel shows the section between 4-8 s in higher temporal resolution. 


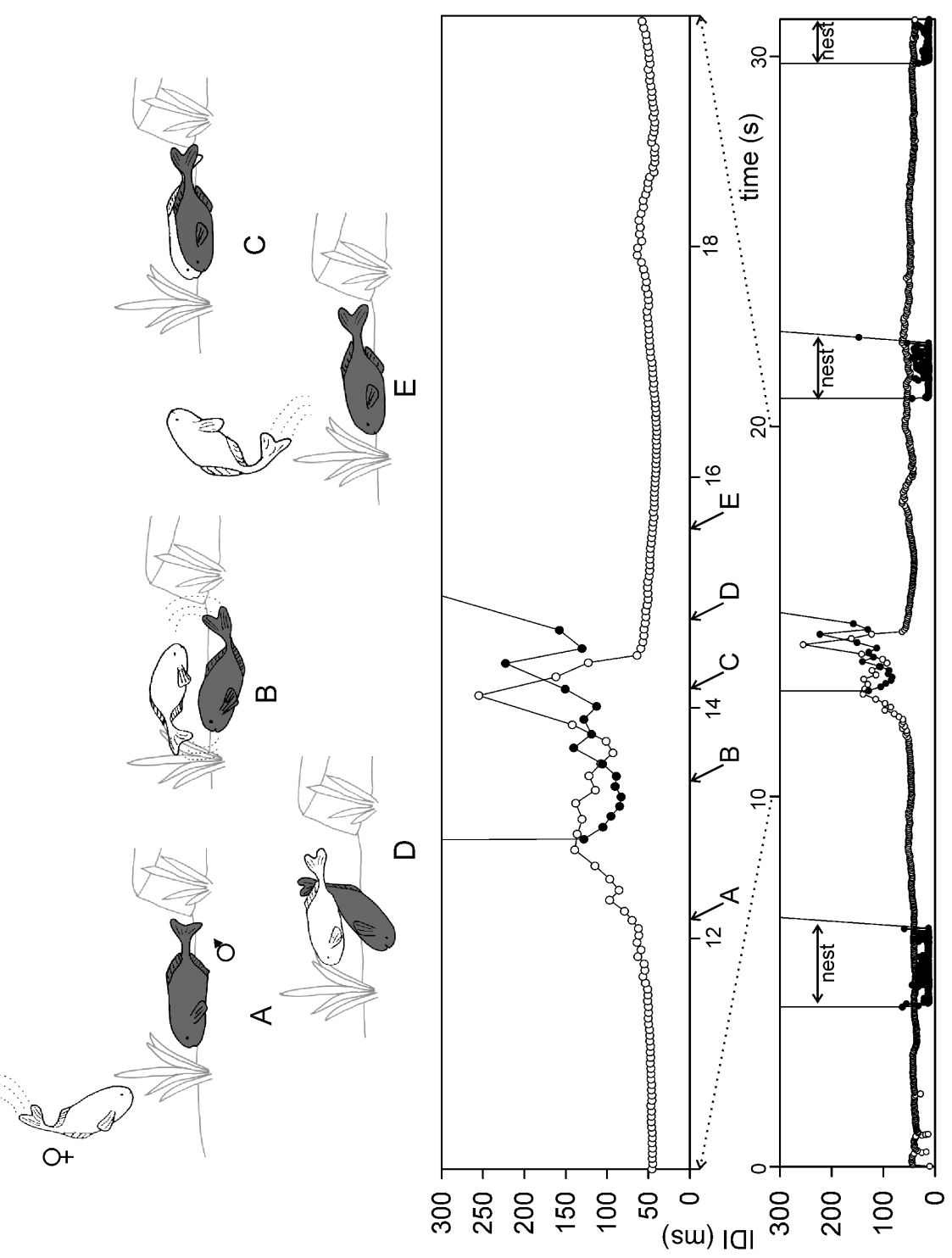


of $P$. castelnaui and in two pairs of $P$. marianne. IDI histogram modes were almost identical, with $13.3 \mathrm{~ms}$ and $46.6 \mathrm{~ms}$ in $P$ castelnaui (5007 IDIs in $340 \mathrm{~s}$ ) and $13.3 \mathrm{~ms}$ and $41.8 \mathrm{~ms}$ in P. marianne (1428 IDIs in $57 \mathrm{~s}$ ).

Highly stereotyped IDI patterns accompanied the reproductive behaviour in members of both species (Figure 10). All spawning bouts observed were similar in that (1) the female displayed a highly regularised IDI pattern when approaching the male and visiting his territory, (2) the male's discharge cessation preceded the female's arrival at the site, and (3) the synchronised IDI pattern in both fish occurred during anal fin contact (which we presume was spawning). The female's resuming a regular IDI pattern on leaving the spawning site was also typical for both species, absent only when the male attacked the female in the 'early' visits of a spawning night (Figure 10B, D, J). The regular patterns of the females before a spawning bout consisted of IDIs with a mean duration of $50-65 \mathrm{~ms}$ in both species for the last 25 pulses before the male's first pulse. Males of both species only began discharging for the spawning bout when the female lowered her discharge rate to about $5 \mathrm{~Hz}$, and when a parallel position was reached. During the spawning interaction both female and male discharged irregularly at a low rate. At the level of the descriptive statistics for spawning bouts given in Tables 3 and 4 there is very little differentiation between the two species.

Sequences of preferred latencies of one individual's EODs to those of the other (review: Kramer, 1996, p. 71-73) were not detected in selected sequences representing all behavioural contexts studied (Figures 4 and 11). This result, of course, is not final proof against the possibility of preferred latency responses in dwarf stonebashers.

\section{Playback of 'swimming' IDI sequences}

All experimental subjects responded to the onset of playback by swimming to, probing or even 'attacking' the dipoles, behaviours not observed before or after playback. Among five $P$. castelnaui not a single one showed a significant preference for one species' IDI sequences compared to those of the

Figure 8. Spawning in P. castelnaui. Female, white; male, grey. The lower panel shows a sequence of $33 \mathrm{~s}$, three nest checkings by the male are marked. The time from 10-20 s, when spawning occurs, is magnified in the upper panel. (A) The female approaches the spawning site. (B) Circling. (C) Parallel position of the two fish. (D) Spawning posture. (E) Female leaves the spawning site. 


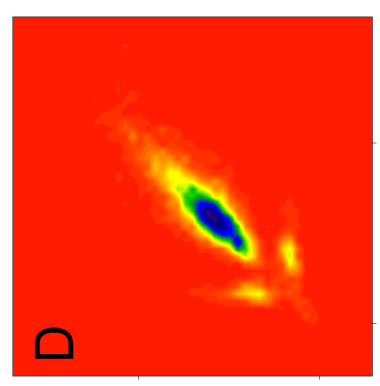

$\stackrel{8}{\circ}$

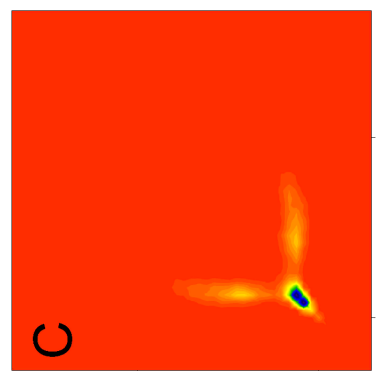

$\stackrel{8}{\circ}$

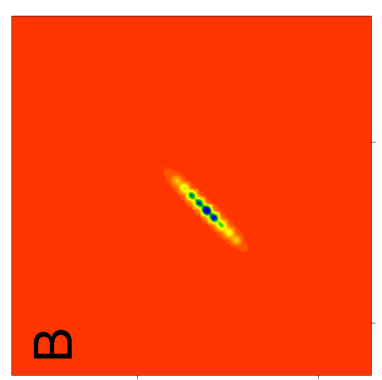

웅

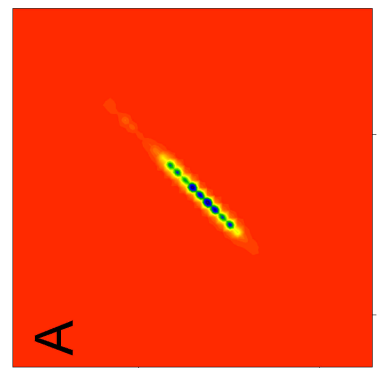

웅

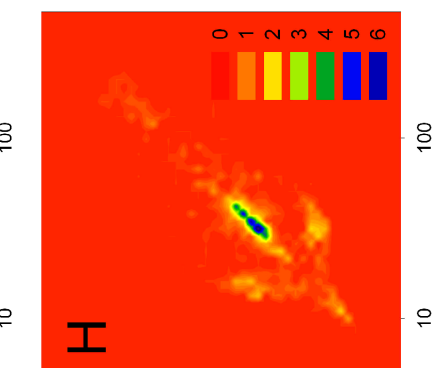

웅

$\div$
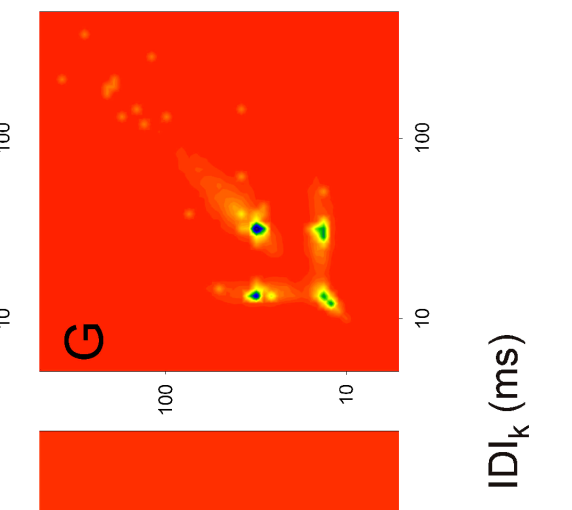

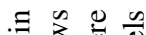

运造

$\theta$ के

呅

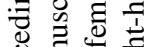

记

巳્ّ

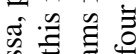

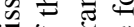

उ

\&

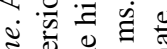

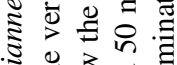

충

ఏ寻寻

人.

ए ब

㱐

壳

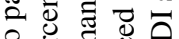

웡

¿巳

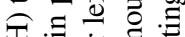

立 合

记

()

ह $\cong \bar{E}$

ป

ธิ.00

氝

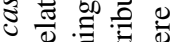

.

Q

$43 \pi$

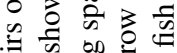

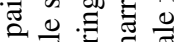

矛寻

¿ $0 \pm 0$

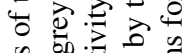

ป 00 .

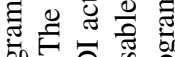

司等

욜

$.2 \Xi \&$ का

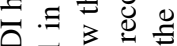

- $-2=$

元十步衣

之曲焉

Фै छ

曰

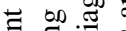

$\Xi \Xi$

$\circ$ \&

ลิ을 夏

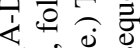

400

- 䒕 U

ब

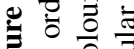

ô 0 施 
other species, measured as time spent close to a signal source for both IDI patterns per species combined (between-species comparisons, Table 5). Only one $P$. marianne individual was tested for shortage of individuals and showed no preference either (Table 5). The other $P$. marianne of the laboratory population were busy reproducing and not available for playback tests.

The differences in visiting times between the two playback IDI sequences within a species were considerable in certain individuals. We tested the hypothesis that there was no difference by one-way ANOVA for each individual separately, using the four IDI sequences as categories. Two $P$. castelnaui showed significant differences among the visiting times for the four playback IDI sequences (Pc D: $F_{3,28}=3.735, p=0.0224$; Pc E: $F_{3,28}=3.795$, $p=0.0212$ ). Post-tests revealed a preference for playback sequence $P$. castelnaui-IDI 2 over P. castelnaui-IDI 1 in experimental subjet Pc D, and even a 'wrong' preference for sequence $P$. marianne-IDI 2 over $P$. castelnaui-IDI 1 in experimental subject Pc E.

\section{Discussion}

Similar to all mormyrid species that have been studied so far (reviews: Kramer, 1990, 1996; Moller, 1995; Carlson, 2002), both dwarf stonebasher species showed broad IDI ranges for isolated specimens during diurnal resting and nocturnal swimming. In earlier studies the experimental subjects of other species discriminated against playback IDI patterns recorded from heterospecific specimens during nocturnal swimming, and preferred conspecific ones (Kramer \& Lücker, 1990; Kramer \& Kuhn, 1994). The two dwarf stonebasher species of the present study, however, did not show any differentiation neither in 'swimming' nor in 'resting' IDI patterns we were able to discern, and no preference for 'swimming' IDI patterns was seen in playback experiments (Table 2).

The species studied by Kramer \& Lücker (1990) belonged to different genera with obvious differentiations in morphology and behaviour. Even though the experimental subjects of Kramer \& Kuhn (1994) were of the same genus, their morphology and big maximum species size difference (1:2) suggests they are not very closely related, and this is confirmed by Feulner et al. (2006). 


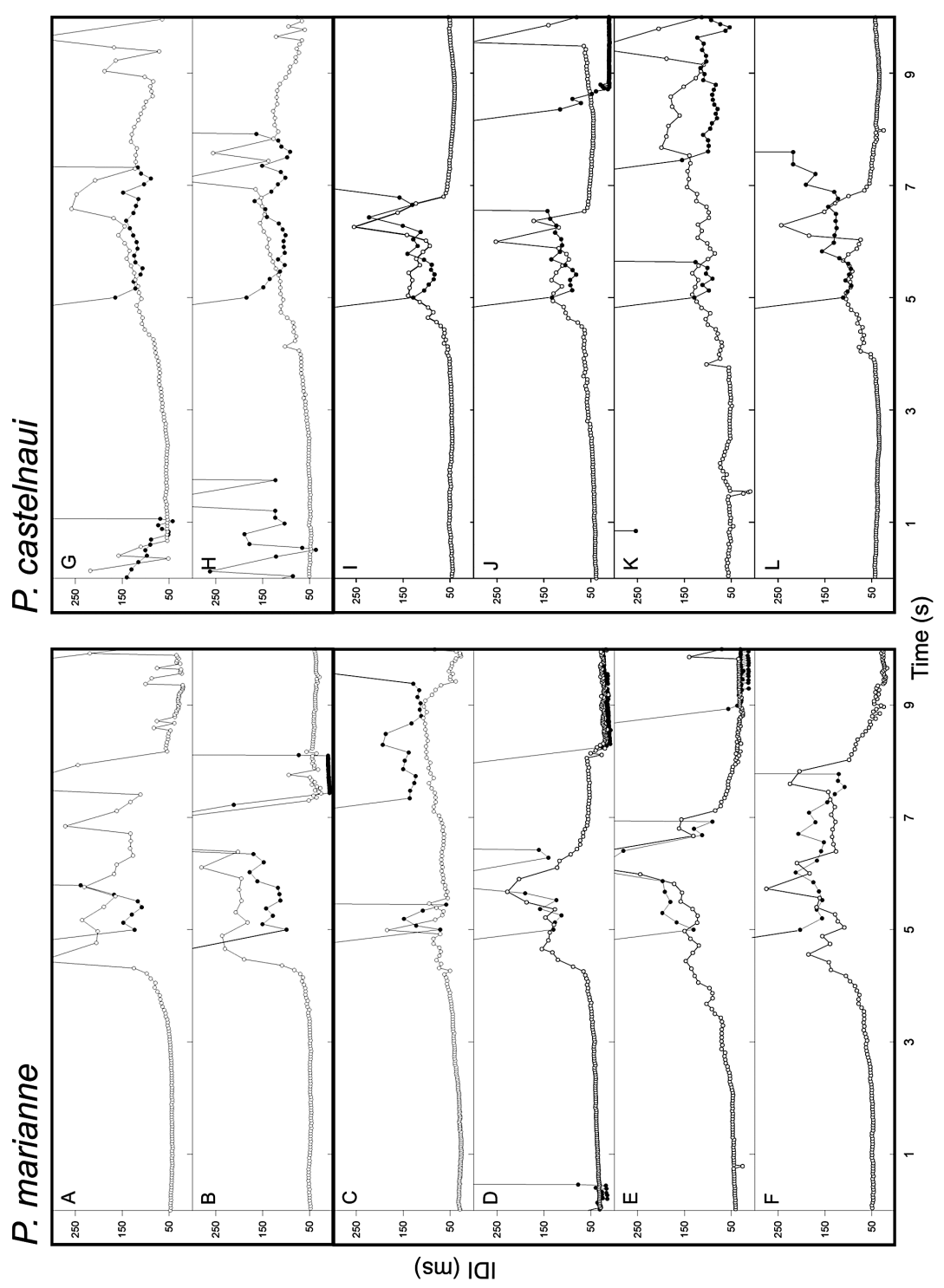


Table 3. Mean IDI (ms) in female $P$. castelnaui $(\mathrm{Pc})$ and $P$. marianne $(\mathrm{Pm})$ for the last 50 IDIs before the males' first EOD of the spawning bout.

\begin{tabular}{lcccr}
\hline Individual & Mean 0 to -25 & SD & Mean -26 to -50 & SD \\
\hline Pc1 & 56.1 & \pm 7.3 & 51.7 & \pm 11.7 \\
Pc2 & 66.4 & \pm 10.0 & 53.7 & \pm 9.9 \\
Pc3 & 68.2 & \pm 15.5 & 54.1 & \pm 7.1 \\
Pm1 & 57.7 & \pm 8.0 & 42.7 & \pm 4.2 \\
Pm2 & 53.6 & \pm 0.9 & 45.7 & \pm 1.8 \\
\hline
\end{tabular}

Table 4. Descriptive statistics for spawning bouts in $P$. castelnaui and $P$. marianne. The start of a spawning bout was defined by a visiting female's sudden EOD rate decrease, when a subsequent $\mathrm{IDI}_{k+1}$ was greater by $10 \mathrm{~ms}$ than a preceding $\mathrm{IDI}_{\mathrm{k}}$, and the end of a spawning bout was defined in a similar way, when a subsequent female $\mathrm{IDI}_{\mathrm{k}+1}$ was less than $10 \mathrm{~ms}$ than the preceding $\mathrm{IDI}_{\mathrm{k}}$.

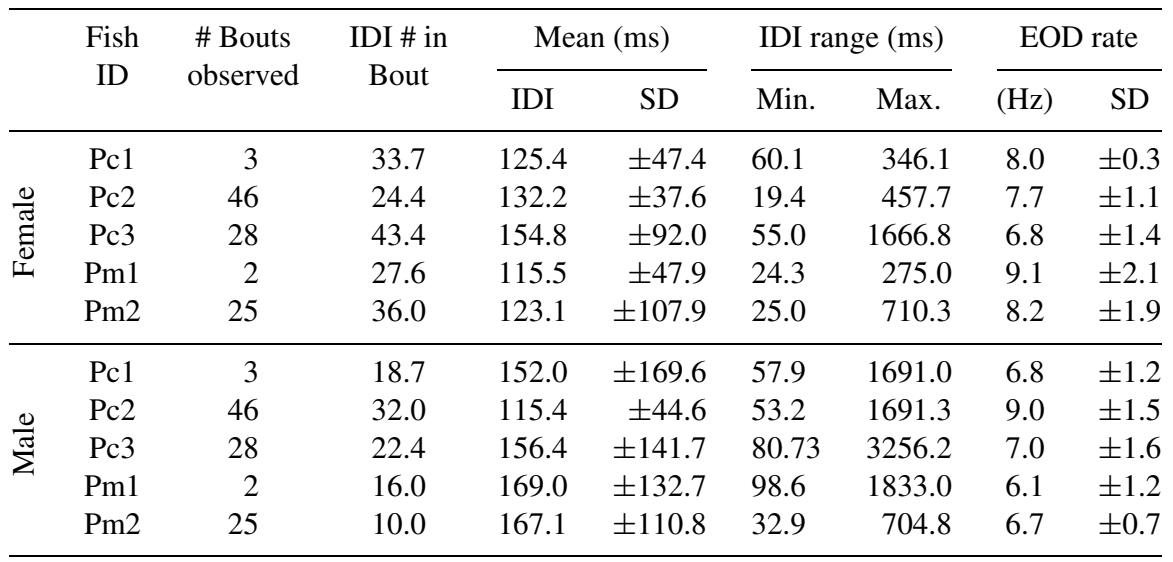

The most relevant social behaviour with respect to species differentiation is reproduction which has been studied in $P$. adspersus, Marcuse-

Figure 10. Comparison of the spawning IDI patterns in P. castelnaui and P. marianne. IDI sequence plots for four different dwarf stonebasher pairs during spawning. White, female IDIs; black, male IDIs. (A-F) P. marianne, (G-L) P. castelnaui. For better comparison all plots are centered on the first male discharge in a spawning bout, referred to as ' $5 \mathrm{~s}$ '. The interactions in B, D and $\mathrm{J}$ were terminated by an attack of the male at the female. These attacks were accompanied by HD displays as shown on the graphs. 

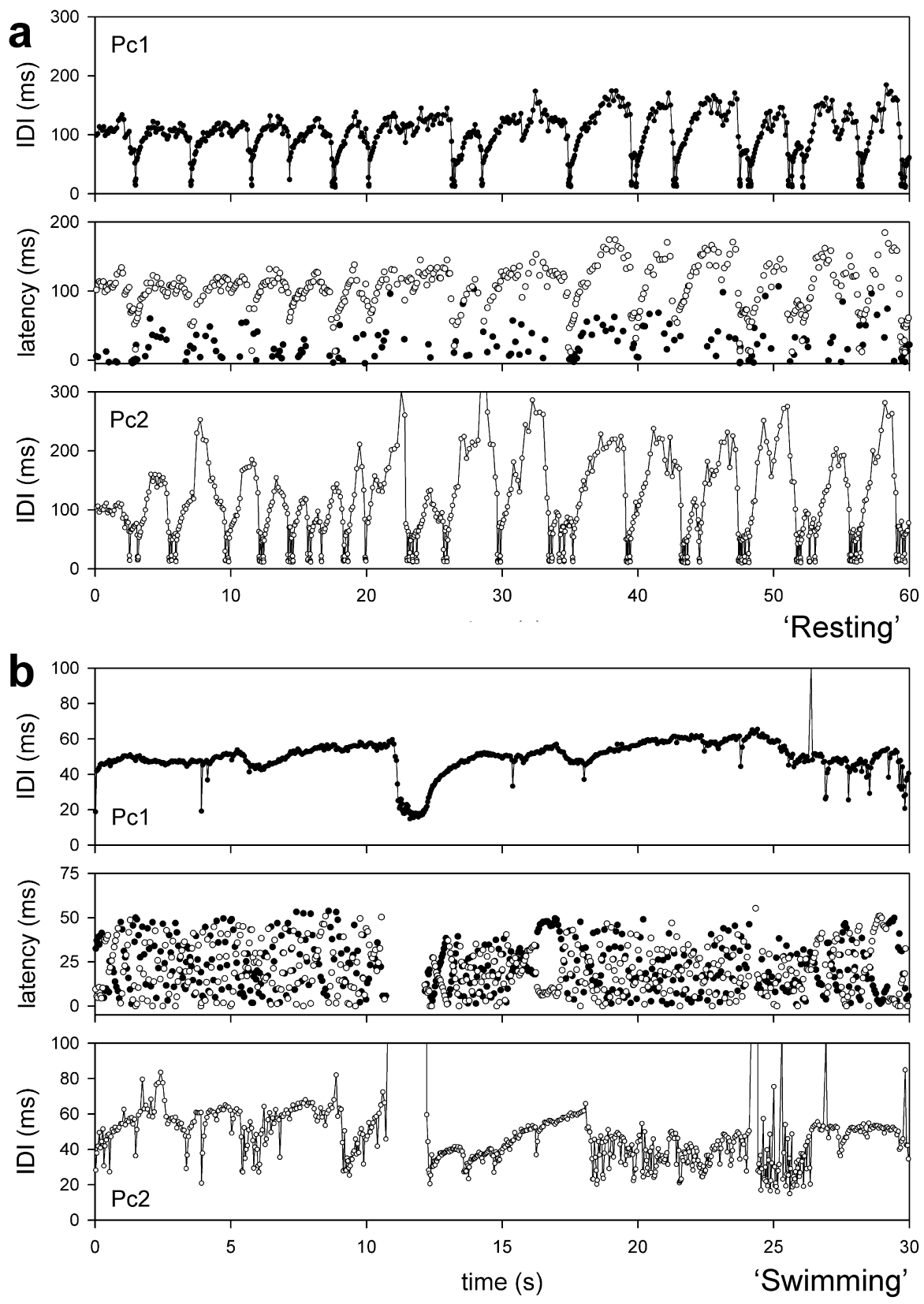
Table 5. Preference of $P$. castelnaui and $P$. marianne for conspecific vs heterospecific IDI playback sequences, measured as time close to stimulus source.

Playback IDI-pattern from:

\begin{tabular}{|c|c|c|c|c|c|c|c|}
\hline \multicolumn{2}{|c|}{ Exp. subject } & \multicolumn{2}{|c|}{ P. castelnaui } & \multicolumn{2}{|c|}{ P. marianne } & \multicolumn{2}{|c|}{ Paired $t$-test } \\
\hline IDI \# & Sex & Time (s) & SE & Time (s) & SE & $t_{15}$ & $p$ \\
\hline Pc A & $\sigma^{T}$ & 74.3 & \pm 17.3 & 66.4 & \pm 17.4 & 0.236 & 0.82 \\
\hline Pc B & $\sigma^{x}$ & 59.8 & \pm 14.7 & 67.6 & \pm 12.2 & 0.313 & 0.76 \\
\hline $\mathrm{Pc} \mathrm{C}$ & q & 87.2 & \pm 10.3 & 58 & \pm 8.7 & 1.477 & 0.14 \\
\hline Pc D & 우 & 81.5 & \pm 9.7 & 75.81 & \pm 10.9 & 0.281 & 0.78 \\
\hline Pc E & $\sigma^{\pi}$ & 50.4 & \pm 13.8 & 107.7 & \pm 14.7 & 2.027 & 0.06 \\
\hline Pm A & q & 60.7 & \pm 6.5 & 54.9 & \pm 7.2 & 0.512 & 0.62 \\
\hline
\end{tabular}

nius macrolepidotus (South African form), and the two dwarf stonebashers, $P$. castelnaui and P. marianne (present paper). The two dwarf stonebasher species differ from $P$. adspersus in (1) the electrical silence of male dwarf stonebashers during female approaches to the spawning site versus slightly regularised IDI sequences in male $P$. adspersus, (2) the highly regular discharge pattern of about 50-ms IDIs in the female that accompanied all courtship and spawning visits in dwarf stonebashers but in $P$. adspersus only in precourtship visits (Bratton \& Kramer, 1989), and (3) the discharge behaviour of males at the nest site with regular double pulse patterns, with alternating IDIs of either 8-12 ms (short) or 16-100 ms (long duration; Figures 7 and 8) in dwarf stonebashers, compared to a wide range of IDIs between 80 and $300 \mathrm{~ms}$ at discharge rates between 3.3 and $12.5 \mathrm{~Hz}$ in $P$. adspersus (Bratton \& Kramer, 1989).

A comparison with the more distantly related Marcusenius macrolepidotus (South African form) reveals still more differentiation in the reproductive behaviour of mormyrids. For example, M. macrolepidotus practises no brood care, and courtship is so cryptic it could not be documented, but highly stereotyped IDI patterns during spawning also occur in this species. Immedi-

Figure 11. (a, b) 'Preferred latencies' in a pair of $P$. castelnaui (middle panels). (a) IDI sequences recorded from individuals Pc1 and Pc2 during day-time; (b) as a, but during nocturnal swimming. Note absence of sequences of preferred latencies. In (a) the resting fish were hiding about $15 \mathrm{~cm}$ apart, while the distance between the swimming fish in (b) ranged from $1-20 \mathrm{~cm}$. 
ately preceding egg release the $M$. macrolepidotus female displayed a regular pattern of about 50-ms IDIs, whereupon the male also showed a stereotyped IDI pattern (Werneyer \& Kramer, 2005, their Fig. 10) similar to those seen in the dwarf stonebasher species and in P. adspersus. These stereotyped IDI patterns may play a role in synchronised gamete release which is required in mormyrids because of their aflagellate spermatozoa (Mattei et al., 1972; Mattei, 1991).

Regularisations at a medium discharge rate seem to be a general nonagressive signal not only in intraspecific (Scheffel \& Kramer, 1997; Arnegard \& Carlson, 2005), but also in interspecific communication (Scheffel \& Kramer, 2000, 2006), while contrasting discharge rates, like HD displays followed by abrupt discharge cessations, or regular double pulse patterns of IDIs of very different lengths, serve as aggressive (reviews: Kramer, 1990, 1996; Moller, 1995; Carlson, 2002) and threat signals (e.g. Bauer, 1972; Bell et al., 1974; Kramer, 1976; Kramer \& Bauer, 1976). This might be the reason for the significant preferences for more regular IDI sequences observed in two experimental subjects in the playback experiments.

The observation that there was very little difference between the IDI sequences generated by $P$. castelnaui and $P$. marianne reflects their close relationship rather than a general irrelevance and lack of information content of IDI patterns in different mormyrid fish species, as demonstrated in the playback experiments of Lücker \& Kramer (1990) and Kramer \& Kuhn (1994). The well-differentiated EOD waveforms (Kramer et al., 2003), and acoustic mating songs of the males (Lamml \& Kramer, 2006), seem to provide sufficient cues for species recognition and mate selection in dwarf stonebashers. Differential selection has probably focussed on the fixed part of the EOD, its waveform, and not so much on the variable part, IDI patterns, in the speciation of $P$. castelnaui and P. marianne. Species-specifity of IDI patterns, as observed in less closely related mormyrid species pairs, may evolve after a longer separation time than the one million years (Kramer et al., 2003) assumed for the separation of the two species studied here.

\section{References}

Arnegard, M.E. \& Carlson, B.A. (2005). Electric organ discharge patterns during group hunting by a mormyrid fish. - Proc. R. Soc. Lond. B 272: 1305-1314.

Bauer, R. (1972). High electrical discharge frequency during aggressive behavior in a mormyrid fish (Gnathonemus petersii). — Experientia 28: 669-670. 
Bell, C.C., Meyers, J.P. \& Rusell, C.J. (1974). Electric organ discharge patterns during dominance related behavioral displays in Gnathonemus petersii (Mormyridae). — J. Comp. Physiol. 92: 201-228.

Bennett, M.V.L. (1971). Electric organs. - In: Fish Physiology, Vol. 5 (Hoar, W.S. \& Randall, D.J., eds). Academic Press, New York, NY, p. 347-491.

Boulenger, G.A. (1911). Catalogue of the fresh-water fishes of Africa in the British Museum (Natural History). — London. Cat. Fresh-water Fish. Africa. i-xii + 1-529.

Bratton, B.O. \& Kramer, B. (1989). Patterns of the electric organ discharge during courtship and spawning in the mormyrid fish, Pollimyrus isidori. - Behav. Ecol. Sociobiol. 24: 349-368.

Carlson, B.A. (2002). Electric signaling behaviour and the mechanisms of electric organ discharge production in mormyrid fish. - J. Physiol. (Paris) 96: 405-419.

Cochran, W.G. \& Cox, G.M. (1957). Experimental designs. $-2^{\text {nd }}$ edn. Wiley, New York, NY.

Crawford, J.D. (1991). Sex recognition by electric cues in a sound-producing mormyrid fish, Pollimyrus isidori. - Brain Behav. Evol. 38: 20-38.

Crawford, J.D. (1992). Individual and sex specifity in the electric organ discharges of breeding mormyrid fish (Pollimyrus isidori). — J. exp. Biol. 164: 79-102.

Crawford, J.D. \& Huang, X. (1999). Communication signals and sound production mechanisms of mormyrid electric fish. - J. exp. Biol. 202: 1417-1426.

Feulner, P.G.D., Kirschbaum, F., Mamonekene, V., Ketmaier, V. \& Tiedemann, R. (2006). Adaptive radiation in African weakly electric fish (Teleostei: Mormyridae: Campylomormyrus); a combined molecular and morphological approch. - J. Evolution. Biol. 20: 403-414.

Hopkins, C.D. (1980). Evolution of electric communication channels of mormyrids. - Behav. Ecol. Sociobiol. 7: 1-13.

Hopkins, C.D. (1981). On the diversity of electric signals in a community of mormyrid electric fish in West Africa. - Am. Zool. 21: 211-222.

Hopkins, C.D. (1999). Design features for electric communication. J. Exp. Biol. 202: 12171228.

Hopkins, C.D. \& Bass, A.H. (1981). Temporal coding of species recognition signals in an electric fish. - Science 212: 85-87.

Iles, R.B. (1960). External sexual differences and their significance in Mormyrus kannume Forskål 1775. — Nature 188: 516.

Kramer, B. (1976). Flight-associated discharge pattern in a weakly electric fish, Gnathonemus petersii (Mormyridae, Teleostei). — Behaviour 59: 88-95.

Kramer, B. (1979). Electric and motor responses of the weakly electric fish, Gnathonemus petersii (Mormyridae), to play-back of social signals. - Behav. Ecol. Sociobiol. 6: 6779.

Kramer, B. (1990). Electrocommunication in teleost fishes: Behavior and experiments. Springer-Verlag, Berlin.

Kramer, B. (1996). Electroreception and communication in fishes. - Stuttgart: Gustav Fischer Verlag.

Kramer, B. (1997). Electric organ discharges and their relation to sex in mormyrid fishes. Naturwissenschaften 84: 119-121.

Kramer, B. \& Bauer, R. (1976). Agonistic behaviour and electric signaling in a mormyrid fish, Gnathonemus petersii. — Behav. Ecol. Sociobiol. 1: 45-61. 
Kramer, B. \& Kuhn, B. (1994). Species recognition by the sequence of discharge intervals in weakly electric fishes of the genus Campylomormyrus (Mormyridae, Teleostei). Anim. Behav. 48: 435-445.

Kramer, B. \& Lücker, H. (1990). Species recognition by EOD interval pattern. — In: Electrocommunication in Teleost Fishes: Behavior and Experiments (Kramer, B., ed.). Springer-Verlag, Berlin, p. 157-170.

Kramer, B., Van der Bank, H., Wink, M., Flint, N. \& Sauer-Gürth, H. (2003). Evidence for parapatric speciation in the mormyrid fish, Pollimyrus castelnaui (Boulenger, 1911), from the Okavango-Upper Zambezi River systems: P. marianne sp. nov., defined by electric organ discharges, morphology and genetics. - Environ. Biol. Fishes 67: 47-70.

Kramer, B. \& Weymann, D. (1987). A microprocessor system for the digital synthesis of pulsed or continuous discharges of electric fish (or animal vocalizations). - Behav. Brain Res. 23: 167-174.

Lamml, M. \& Kramer, B. (2005). Sound production in the reproductive behaviour of the weakly electric fish Pollimyrus marianne Kramer et al. 2003 (Mormyridae, Teleostei). - Bioacoustics 15: 51-78.

Lamml, M. \& Kramer, B. (2006). Differentiation of courtship songs in prapatric sibling species of dwarf stonebashers from southern Africa (Mormyridae, Teleostei). - Behaviour 143: 783-810.

Martin, P. \& Bateson, P. (1993). Measuring Behaviour. $-2^{\text {nd }}$ edn. University Press, Cambridge, p. 84 .

Mattei, X. (1991). Spermatozoon ultrastructure and its systematic implications in fishes. Can. J. Zool. 69: 3038-3055.

Mattei, X., Mattei, J., Reizer, C. \& Chevalier, J.L. (1972). Ultrastructure des spermatozoïdes aflagellés des mormyres (poissons téléostéens). - J. Microscopie 15: 67-78.

Moller, P. (1995). Electric fishes: History and behavior. — Chapman \& Hall, London.

Scheffel, A. \& Kramer, B. (1997). Electrocommunication and social behaviour in Marcusenius senegalensis (Mormyridae, Teleostei). - Ethology 103: 404-420.

Scheffel, A. \& Kramer, B. (2000). Electric signals in the social behavior of sympatric elephantfish (Mormyridae, Teleostei) from the Upper Zambezi River. - Naturwissenschaften 87: 142-147.

Scheffel, A. \& Kramer, B. (2006). Intra- and interspecific electrocommunication among sympatric mormyrids in the Upper Zambezi River. - In: Communication in fishes (Ladich, F., Collin, S.P., Moller, P. \& Kapoor, B.G., eds). Science Publishers, Enfield, New Hampshire, USA, p. 733-753.

Skelton, P.H. (2001). A complete guide to the freshwater fishes of southern Africa. $-2^{\text {nd }}$ edn. Struik Publishers, Cape Town.

Werneyer, M. \& Kramer, B. (2002). Intraspecific agonistic interactions in freely swimming mormyrid fish, Marcusenius macrolepidotus (South African form). - J. Ethol. 20: 107121.

Werneyer, M. \& Kramer, B. (2005). Electric signalling and reproductive behaviour in a mormyrid fish, the bulldog Marcusenius macrolepidotus (South African form). J. Ethol. 23: 113-125. 